OPEN ACCESS

Edited by:

Andreas Charidimou, Harvard Medical School, USA

Reviewed by:

Gregoire Boulouis,

Paris Descartes University, France

Vincent Thijs,

Florey Institute of Neuroscience and Mental Health, Australia

*Correspondence:

Wengui Yu

wyu@uci.edu

Specialty section: This article was submitted to Stroke,

a section of the journal

Frontiers in Neurology

Received: 04 March 2017

Accepted: 18 April 2017

Published: 03 May 2017

Citation:

Hong D, Stradling D, Dastur CK, Akbari Y, Groysman L, Al-Khoury L, Chen J, Small SL and Yu W (2017)

Resistant Hypertension after

Hypertensive Intracerebral Hemorrhage Is Associated with More Medical Interventions and

Longer Hospital Stays without Affecting Outcome.

Front. Neurol. 8:184.

doi: 10.3389/fneur.2017.00184

\section{Resistant Hypertension after Hypertensive Intracerebral Hemorrhage Is Associated with More Medical Interventions and Longer Hospital Stays without Affecting Outcome}

\section{Daojun Hong ${ }^{1,2}$, Dana Stradling ${ }^{1}$, Cyrus K. Dastur ${ }^{1}$, Yama Akbari ${ }^{1}$, Leonid Groysman ${ }^{1}$, Lama Al-Khoury ${ }^{1}$, Jefferson Chen ${ }^{3}$, Steven L. Small ${ }^{1}$ and Wengui Yu ${ }^{1 *}$}

\begin{abstract}
'Department of Neurology, University of California at Irvine, Irvine, CA, USA, ${ }^{2}$ Department of Neurology, The First Affiliated Hospital, Nanchang University, Nanchang, Jiangxi, China, ${ }^{3}$ Department of Neurosurgery, University of California at Irvine, Irvine, CA, USA
\end{abstract}

Background: Hypertension (HTN) is the most common cause of spontaneous intracerebral hemorrhage $(\mathrm{ICH})$. The aim of this study is to investigate the role of resistant HTN in patients with $\mathrm{ICH}$.

Methods and results: We conducted a retrospective study of all consecutive $\mathrm{ICH}$ admissions at our medical center from November 2013 to October 2015. The clinical features of patients with resistant HTN (requiring four or more antihypertensive agents to keep systolic blood pressure $<140 \mathrm{~mm} \mathrm{Hg}$ ) were compared with those with responsive HTN (requiring three or fewer agents). Of the 152 patients with hypertensive $\mathrm{ICH}, 48$ (31.6\%) had resistant HTN. Resistant HTN was independently associated with higher body mass index and proteinuria. Compared to the responsive group, patients with resistant HTN had higher initial blood pressures and greater requirement for ventilator support, hematoma evacuation, hypertonic saline therapy, and nicardipine infusion. Resistant HTN increases length of stay (LOS) in the intensive care unit (ICU) (4.2 vs 2.1 days; $p=0.007$ ) and in the hospital (11.5 vs 7.0 days; $p=0.003$ ). Multivariate regression analysis showed that the rate of systolic blood pressure $>140 \mathrm{~mm} \mathrm{Hg}$ and duration of nicardipine infusion were independently associated with LOS in the ICU. There was no significant difference in hematoma expansion and functional outcome at hospital discharge between the two groups.

Conclusion: Resistant HTN in patients with ICH is associated with more medical interventions and longer LOS without effecting outcome at hospital discharge.

Keywords: intracerebral hemorrhage, resistant hypertension, intensive care unit, length of stay, functional outcome 


\section{INTRODUCTION}

Uncontrolled hypertension (HTN) is the most common cause of spontaneous intracerebral hemorrhage (ICH) $(1,2)$. Hypertensive $\mathrm{ICH}$ is a type of stroke with intraparenchymal bleeding from hypertensive damage to blood vessel walls. Chronic HTN produces microangiopathy characterized by lipohyalinosis, fibrinoid necrosis, and development of Charcot-Bouchard aneurysms, affecting penetrating arteries throughout the brain. The predilection sites for hypertensive ICH include the basal ganglia (40-50\%), lobar regions (20-50\%), thalamus (10-15\%), pons (5-12\%), cerebellum (5-10\%), and other brainstem sites (1-5\%) $(3,4)$.

Data from numerous studies have identified high systolic blood pressure (SBP) as the major risk factor for ICH (5-7). SBP variability predicts poor outcome and neurological deterioration (8-10).

Two large randomized controlled trials have demonstrated that early intensive lowering of SBP to less than $140 \mathrm{~mm} \mathrm{Hg}$ is safe without significant outcome impact $(11,12)$. Acute lowering of SBP to $140 \mathrm{~mm} \mathrm{Hg}$ has been recommended for the management of spontaneous ICH (13).

However, it is challenging to promptly and effectively control SBP in patients at risk for resistant HTN (14-17). Resistant HTN is defined as blood pressure that remains above normal despite of concurrent use of three antihypertensive agents of different classes $(15,16)$. Data derived from cross-sectional studies and post hoc analyses of clinical trials have estimated the prevalence of resistant HTN to be about $8-15 \%$ of all patients being treated for $\operatorname{HTN}(17,18)$. Currently, little is known about resistant HTN in patients with ICH. We sought to evaluate the potential role of resistant HTN in ICH.

\section{MATERIALS AND METHODS}

\section{Patients}

All consecutive ICH admissions at the University of California, Irvine Medical Center between November 2013 and October 2015 were reviewed retrospectively. The patient list was compiled by searching the electronic medical record using International Classification of Diseases Ninth Revision code 431 and by stroke center primary data collection for the AHA Getting with the Guidelines registry. We then conducted extensive chart review to identify those with hypertensive ICH.

\section{Study Protocol}

The screening of hypertensive ICH is described in Figure $\mathbf{1 .}$ Exclusion criteria included death or comfort care within $72 \mathrm{~h}$ of admission, all non-hypertensive $\mathrm{ICH}$, isolated intraventricular hemorrhage, and ICH with subdural hemorrhage. Nonhypertensive ICH was defined as primary ICH without clinical evidence of HTN during the hospital stay. Patients with both HTN and cerebral amyloid angiopathy (CAA) or coagulopathy were counted as hypertensive ICH.

Hypertensive ICH patients were divided into two groups: patients on four or more antihypertensive agents at discharge (resistant group) and patients on three or fewer antihypertensive agents (responsive group) per AHA guidelines (15).

The following demographics and medical history were collected for patients with hypertensive ICH: age, gender, race, body mass index (BMI), social history, medical history, and home medications (antiplatelet, anticoagulant, and antihypertensive agents). Clinical data collected were initial SBP and diastolic blood pressure, Glasgow coma scale score, hyponatremia, serum creatinine, urine protein, ICH location, ICH volume, midline shift, ICH score, ICH volume increase within $24 \mathrm{~h}$, fever $\left(>38^{\circ} \mathrm{C}\right)$, pneumonia or other infections, deep vein thrombosis (DVT), seizure activities, rate of SBP $>140 \mathrm{~mm} \mathrm{Hg}$ during the intensive care unit (ICU) stay, ventilator support, external ventricular drainage (EVD), hematoma evacuation, use of hypertonic saline, duration of nicardipine infusion, length of stay (LOS) in the ICU and the hospital, disposition, number of oral antihypertensive agents, and modified Rankin Scale (mRS) score at discharge.

The ICH volume was calculated by the ABC/2 formula (18). The ICH score was estimated as previously described (19). ICH location was classified as deep (basal ganglia or thalamus), lobar, brain stem, or cerebellar. Midline shift was measured at the level of the septum pellucidum on CT scan. The outcome at discharge was divided into favorable functional recovery with mRS scores 0-3 and unfavorable functional recovery with mRS scores 4-6. Disposition was classified as self-destination (home or acute rehabilitation facility), dependent destination (acute care facility or skilled nursing facility), or death.

\section{Statistical Analysis}

Data analyses were performed using SPSS software. Categorical or dichotomous variables were expressed as frequency distribution and percentages. Group comparisons of variables were performed using the chi-square test, Fisher exact test, Student's t-test, or Mann-Whitney test as appropriate. Correlation analyses between variables were evaluated using Pearson's correlation coefficient. Multivariate linear regression was performed to assess the independent effect of variables. A $p$ value of 0.05 or less was considered significant.

\section{RESULTS}

\section{Resistant HTN in Patients with ICH}

Of the $244 \mathrm{ICH}$ admissions, 152 patients met the inclusion criteria for hypertensive ICH and 92 patients were excluded due to early death, non-hypertensive causes, or unknown etiology (Figure 1). There were 48 patients $(31.6 \%)$ in the resistant group and 104 $(68.4 \%)$ in the responsive group.

\section{Clinical Characteristics of Patients with Resistant and Responsive HTN}

The baseline characteristics of the two study groups are shown in Table 1. The patients with resistant HTN were associated with younger age, obstructive sleep apnea, chronic renal failure, higher initial blood pressures, increased serum creatinine, and proteinuria. There was no significant difference between the two groups in home use of antithrombotic and antihypertensive medications, ICH volume, location, or severity. After adjustment 


\section{Screening of hypertensive $\mathrm{ICH}$}

$244 \mathrm{ICH}$ patients screened

$$
\downarrow \begin{aligned}
& \text { - Expired within } 72 \text { hours }(n=30) \\
& \text { - Comfort care within } 72 \text { hours }(n=7)
\end{aligned}
$$

$207 \mathrm{ICH}$ patients reviewed

- Vascular etiology $(n=12)$

- Brain tumor $(n=9)$

- Isolated ventricular hemorrhage $(n=7)$

- Coagulopathy without HTN (n=6)

- Infarct with hemorrhagic transformation $(n=5)$

- Cerebral amyloid angiopathy without HTN (n=4)

- Miscellaneous etiology $(n=6)$

- Unknown etiology $(n=6)$

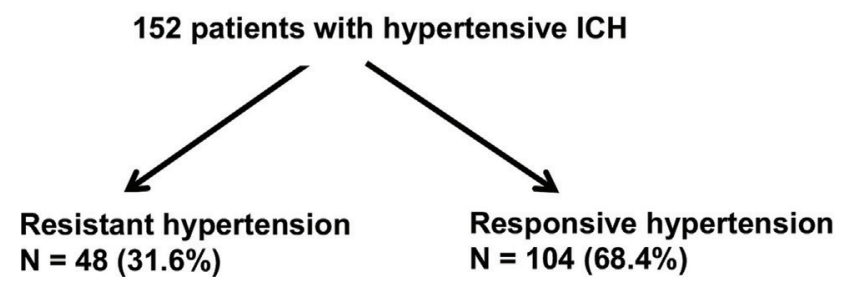

FIGURE 1 | Screening flowchart for patients with hypertensive intracerebral hemorrhage (ICH).

for age, race, and gender, logistic regression analysis showed that BMI (odds ratio, 1.073; 95\% confidence interval, 1.005-1.145; $p=0.034$ ) and proteinuria (odds ratio, 3.204; 95\% confidence interval, $1.440-7.131 ; p=0.004)$ were independently associated with resistant HTN.

\section{Antihypertensive Therapy}

Patients with SBP > $140 \mathrm{~mm} \mathrm{Hg}$ were initially treated with labetalol or hydralazine $10 \mathrm{mg}$ iv pro re nata and nicardipine infusion $2.5-15 \mathrm{mg} / \mathrm{h}$. The intravenous medications were then quickly transitioned to oral antihypertensive agents, starting in the ICU. The commonly used oral antihypertensive agents included calcium channel blocker (CCB) amlodipine, angiotensin-converting enzyme inhibitor (ACE-I) lisinopril or benazepril, angiotensin II receptor blocker (ARB) losartan, diuretics hydrochlorothiazide or spironolactone, $\beta$-blocker metoprolol, $\alpha / \beta$-blocker labetalol or carvedilol, central $\alpha$ agonist clonidine, and vasodilator hydralazine. The oral antihypertensive agents taken by patients at hospital discharge are shown in Table 2. Approximately 29.2\% (14/48) of patients with resistant HTN needed five or more antihypertensive agents. Patients with resistant HTN were more likely to be taking CCB, ACE-I, $\alpha / \beta$ blocker, diuretics, vasodilator, and central $\alpha$-agonist than the responsive group.

\section{Medical Complications, Interventions, and Outcome}

As shown in Table 3, patients with resistant HTN were more likely to have fever, hyponatremia, and non-respiratory infections than those with responsive HTN. Despite higher initial blood pressures (Table 1) and a higher rate of SBP > $140 \mathrm{~mm} \mathrm{Hg}(37.2$ vs $25.2 \%$; $p=0.001$ ) (Table 3 ) in the resistant group, there was no significant difference in average increase of the ICH volume at $24 \mathrm{~h}(3 \pm 6.3$ vs $4 \pm 3.8)$. There was no difference in pneumonia, seizure activities, or DVT between the two groups.

More patients with resistant HTN required intensive interventions such as ventilator support, hypertonic saline therapy, hematoma evacuation, and nicardipine infusion than the responsive group (Table 3 ).

The resistant group also had significantly longer LOS in the ICU (4.2 vs 2.1 days; $p=0.007)$ and hospital (11.5 vs 7.0 days; $p=0.003$ ) than that of the responsive group.

Multivariate linear regression analysis showed that fever ( $\beta$ coefficient $=-0.306 ; t=-3.908 ; p=0.001)$, ventilator support ( $\beta$ coefficient $=-0.280 ; t=-3.840 ; p=0.001)$, and hematoma evacuation ( $\beta$ coefficient $=-0.126 ; t=-2.042 ; p=0.043$ ) were associated with longer LOS in the ICU. After risk adjustment for fever, hyponatremia, infections, ICH score, midline shift, ventilator support, and hematoma evacuation, the rate of SBP $>140 \mathrm{~mm} \mathrm{Hg}(\beta$ coefficient $=0.267 ; t=4.536 ; p=0.001)$ and the duration of nicardipine infusion $(\beta$ coefficient $=0.418$; $t=7.040 ; p=0.001)$ were shown to be independently associated with LOS in the ICU.

There was no significant difference between the two groups in functional outcome (odds ratio, $0.81 ; 95 \%$ confidence interval, $0.40-1.65 ; p=0.559$ ) and disposition at hospital discharge $(p=0.825)$. 
TABLE 1 | Clinical characteristics of ICH patients with resistant or responsive HTN.

\begin{tabular}{|c|c|c|c|}
\hline Variables & Resistant group $(n=48)$ & Responsive group $(n=104)$ & $p$ Value \\
\hline Male & 30 (62.5) & 63 (60.6) & 0.821 \\
\hline Hispanic American & $22(45.8)$ & $48(46.2)$ & \\
\hline Non-Hispanic American & $12(25.0)$ & $29(27.9)$ & \\
\hline Asian-American & $9(18.8)$ & $23(22.1)$ & \\
\hline African-American & $5(10.4)$ & $4(3.8)$ & \\
\hline Diabetes & $16(33.3)$ & $32(30.8)$ & 0.752 \\
\hline Hyperlipidemia & 19 (39.6) & $40(38.5)$ & 0.895 \\
\hline Cardiovascular events & $11(22.9)$ & $13(12.5)$ & 0.102 \\
\hline OSA & $8(16.7)$ & $6(5.8)$ & $0.039^{*}$ \\
\hline Chronic renal failure & $13(27.1)$ & $10(9.6)$ & $0.005^{\star}$ \\
\hline Use of antiplatelet agents & $11(22.9)$ & $23(22.1)$ & 0.912 \\
\hline $3-8$ & $10(20.8)$ & 17 (16.3) & \\
\hline Initial SBP (mm Hg) in ED & $201.5(186.5,223.8)$ & $180.0(157.3,200.0)$ & $0.001^{*}$ \\
\hline Initial DBP $(\mathrm{mm} \mathrm{Hg})$ in ED & $99.5(90.0,123.0)$ & $95.0(79.0,106.8)$ & $0.016^{*}$ \\
\hline $\mathrm{BMI}\left(\mathrm{kg} / \mathrm{m}^{2}\right)$ & $27.8(24.1,33.2)$ & $26.0(23.0,29.7)$ & $0.010^{*}$ \\
\hline Serum creatinine (mg/dL) & $1.0(0.7,1.5)$ & $0.8(0.6,1.0)$ & $0.008^{*}$ \\
\hline Proteinuria & $28(58.3)$ & $35(33.7)$ & $0.004^{\star}$ \\
\hline Initial ICH volume (mL) & $17.4(5.5,32.1)$ & $11.8(4.7,21.6)$ & 0.055 \\
\hline Midline shift (mm) & $0.0(0.0,4.9)$ & $0.0(0.0,3.0)$ & 0.105 \\
\hline $\mathrm{ICH}$ location & & & 0.581 \\
\hline Deep & 28 (58.3) & 69 (66.3) & \\
\hline Lobar & $14(29.2)$ & $21(20.3)$ & \\
\hline Brain stem & $4(8.3)$ & $7(6.7)$ & \\
\hline Cerebellum & $2(4.2)$ & $7(6.7)$ & \\
\hline
\end{tabular}

BMI, body mass index; DBP, diastolic blood pressure; ED, emergency department; GCS, Glasgow coma scale; ICH, intracerebral hemorrhage; IQR, interquartile range; OSA, obstructive sleep apnea; SBP, systolic blood pressure; HTN, hypertension.

Variables are presented as $n(\%)$ in nominal data or median (IQR) in continuous data.

${ }^{*} p<0.05$.

TABLE 2 | The use of antihypertensive agents in resistant and responsive groups.

\begin{tabular}{lccc}
\hline $\begin{array}{l}\text { Antihypertensive } \\
\text { agents }\end{array}$ & $\begin{array}{c}\text { Resistant group } \\
(\boldsymbol{n}=\mathbf{4 8 )}\end{array}$ & $\begin{array}{c}\text { Responsive group } \\
(\boldsymbol{n}=\mathbf{1 0 4 )}\end{array}$ & $\boldsymbol{p}$ Value \\
\hline CCB & $42(87.5)$ & $61(58.7)$ & $0.001^{*}$ \\
ACE-I & $40(83.3)$ & $68(65.4)$ & $0.023^{*}$ \\
$\alpha / \beta$ Blocker & $32(66.7)$ & $37(35.6)$ & $0.001^{*}$ \\
Diuretics & $23(47.9)$ & $11(10.6)$ & $0.001^{*}$ \\
$\beta$ Blocker & $15(31.3)$ & $25(20.0)$ & 0.348 \\
Vasodilator & $31(64.6)$ & $8(7.7)$ & $0.001^{*}$ \\
Central $\alpha$-agonist & $13(27.1)$ & $6(5.8)$ & $0.001^{*}$ \\
ARB & $8(16.7)$ & $11(10.6)$ & 0.291 \\
\hline
\end{tabular}

CCB, calcium channel blocker; ACE-I, angiotensin-converting enzyme inhibitor; ARB, angiotensin I/ receptor blocker.

${ }^{*} p<0.05$.

\section{DISCUSSION}

In this single-center cohort, resistant HTN was found in $31.6 \%$ patients with hypertensive ICH. It was independently associated with higher BMI and proteinuria. Higher BMI might be a risk factor for resistant HTN, while proteinuria likely reflects end organ damage from chronic HTN. Of note, resistant HTN is seen in only $8-15 \%$ of the general hypertensive population $(16,17)$. There appears to be a higher prevalence of resistant HTN in patients with $\mathrm{ICH}$ than in the general hypertensive population. Of note, majority of our ICH patients were Hispanic and Asian. Some of them had never seen a doctor in the past. That may explain the higher prevalence of resistant HTN in our ICH population. There were also significant numbers of patients with lobar or cerebellar hemorrhage in our cohort. Although most of these patients were young and unlikely to have CAA, we cannot rule out the possibility of underlying CAA in some patients.

Medical complications such as fever and infections were reported to increase LOS after $\operatorname{ICH}(20,21)$. In the current study, we demonstrated that patients with resistant HTN had higher rates of medical complications, greater requirement for intensive interventions in the ICU, and longer LOS in the ICU and hospital than patients with responsive HTN. After risk adjustment, the rates of SBP $>140 \mathrm{~mm} \mathrm{Hg}$ and the duration of 
TABLE 3 | Clinical features and outcome of resistant and responsive groups.

\begin{tabular}{|c|c|c|c|c|}
\hline Variables & Resistant group ( $n=48$ ) & Responsive group $(n=104)$ & $p$ Value & OR or $A D(95 \% \mathrm{Cl})$ \\
\hline Fever & $20(41.7)$ & $24(23.1)$ & $0.019^{\star}$ & $2.38(1.14,4.96)$ \\
\hline Hyponatremia & $7(14.6)$ & $4(3.8)$ & $0.018^{*}$ & $4.27(1.19,15.37)$ \\
\hline Pneumonia & $10(20.8)$ & $12(11.5)$ & 0.130 & $2.02(0.80,5.07)$ \\
\hline Other infections & $12(25.0)$ & $12(11.5)$ & $0.034^{*}$ & $2.56(1.05,6.21)$ \\
\hline Deep vein thrombosis & $2(4.2)$ & $4(3.8)$ & 1.000 & $1.09(0.19,6.15)$ \\
\hline Seizure & $2(4.2)$ & $6(5.8)$ & 1.000 & $0.71(0.14,3.65)$ \\
\hline $\mathrm{ICH}$ volume increase at $24 \mathrm{~h}$ & $3(6.3)$ & $4(3.8)$ & 0.679 & $1.67(0.36,7.76)$ \\
\hline External ventricular drainage & 7 (14.6) & $12(11.5)$ & 0.598 & $1.31(0.48,3.57)$ \\
\hline Ventilator support & $23(47.9)$ & $24(23.1)$ & $0.002^{*}$ & $3.07(1.48,6.35)$ \\
\hline Use of hypertonic saline & $14(29.2)$ & $14(13.5)$ & $0.020^{\star}$ & $2.65(1.14,6.13)$ \\
\hline Hematoma evacuation & $9(18.8)$ & $7(6.7)$ & $0.025^{\star}$ & $3.20(1.11,9.19)$ \\
\hline Rate of SBP $>140 /$ SBP $<140$ & $37.2(27.5,53.5)$ & $25.2(15.9,36.1)$ & $0.001^{\star}$ & $12.93(7.97,17.89)$ \\
\hline Rate of DBP $>90 / \mathrm{DBP}<90$ & $2.5(0.5,5.3)$ & $1.6(0.0,4.2)$ & $0.048^{\star}$ & $1.58(-0.73,3.89)$ \\
\hline Duration of nicardipine drip (h) & $81.8(41.0,172.9)$ & $59.0(32.8,111.6)$ & $0.039^{\star}$ & $38.90(6.52,71.28)$ \\
\hline LOS in the ICU (days) & $4.2(1.9,9.4)$ & $2.1(1.3,4.7)$ & $0.007^{\star}$ & $2.30(0.42,4.19)$ \\
\hline LOS in the hospital (days) & $11.5(6.3,16.8)$ & $7.0(5.0,11.0)$ & $0.003^{\star}$ & $3.77(0.02,7.52)$ \\
\hline SBP at discharge $(\mathrm{mm} \mathrm{Hg})$ & $134.5(125.3,146.0)$ & $131.0(119.0,137.8)$ & $0.003^{*}$ & $7.32(2.45,12.20)$ \\
\hline DBP at discharge $(\mathrm{mm} \mathrm{Hg})$ & $70.5(61.3,79.5)$ & $69.0(61.0,78.5)$ & 0.567 & $1.13(-2.76,5.02)$ \\
\hline $\mathrm{mRS}$ at discharge & & & 0.559 & $0.81(0.40,1.65)$ \\
\hline $0-3$ & $17(35.4)$ & $42(40.4)$ & & \\
\hline $4-6$ & $31(64.6)$ & $62(59.6)$ & & \\
\hline Disposition & & & 0.825 & \\
\hline Self-destination & $22(45.8)$ & $53(51.0)$ & & \\
\hline Dependent destination & $22(45.8)$ & $44(42.3)$ & & \\
\hline Death & $4(8.4)$ & $7(6.7)$ & & \\
\hline
\end{tabular}

$A D$, absolute difference; $C I$, confidence interval; $D B P$, diastolic blood pressure; LOS, length of stay; ICH, intracerebral hemorrhage; ICU, intensive care unit; IQR, interquartile range; mRS, modified Rankin scale; OR, odds ratio; SBP, systolic blood pressure.

Variables are presented as $n(\%)$ in nominal data or median (IQR) in continuous data.

${ }^{*} p<0.05$.

nicardipine infusion were independently associated with LOS in the ICU. With intensive BP lowering in both groups, there was no significant difference in average increase of the $\mathrm{ICH}$ volume at $24 \mathrm{~h}$ and functional outcome at hospital discharge.

Our preliminary findings have a number of implications. First, given higher prevalence of resistant $\mathrm{HTN}$ in patients with $\mathrm{ICH}$ than in the general hypertensive population, resistant HTN may be a significant risk factor for ICH and should be treated aggressively in the outpatient setting.

Second, $68.4 \%$ of hypertensive ICH patients had responsive HTN, and approximately $60 \%$ of these patients did not require intensive interventions such as EVD, hematoma evacuation, or ventilation support (Table 3). These findings support the view that patients with minor ICH can be safely monitored in the stepdown unit (22-24).

Third, longer LOS in the ICU is associated with significantly higher health-care costs and burdens on patients and their families $(25,26)$. In view of the lack of outcome benefit from aggressive medical and surgical interventions (11, 12, 27-29), it appears that now it is the time to assess resource utilization in patients with hypertensive ICH. Since higher rates of SBP and prolonged duration of nicardipine infusion were associated with longer LOS in the ICU, early transition from intravenous nicardipine infusion to oral antihypertensive agents in the ICU may potentially reduce LOS and health-care costs.

Finally, little is known about effective management of resistant HTN after ICH. CCB and ACE-I or ARB are widely accepted as first- and second-line drugs for resistant HTN (14).
However, the choice of third- and fourth-line antihypertensive agents varies greatly in the management of hypertensive ICH. Hydrochlorothiazide may not be appropriate for patients with large ICH due to the risk of hyponatremia and worsening perihematoma edema. In a recent randomized trial, spironolactone was shown to be very effective in patients with resistant HTN (30). We have successfully used spironolactone and $\alpha / \beta$-blocker labetalol as the third- and fourth-line oral agents to control resistant HTN and to wean off nicardipine infusion promptly. A proposed oral antihypertensive titration protocol is shown in Figure 2.

Our study has limitations. First, it was retrospective in nature, and resistant HTN was defined after ICH in the acute care setting. In the acute phase, patients with ICH may have significantly elevated BP due to a stress response. However, stress-induced reactive HTN usually responds to antihypertensive therapy promptly and is unlikely to require more than three oral agents for BP control. Second, given small sample size, the study is insufficiently powered to show significant outcome differences between resistant and responsive groups. The lack of 90-day outcome data made it impossible to know the long-term impact of resistant HTN on functional recovery. A larger sample size study with 90-day outcome data is needed to address the issue.

In summary, resistant HTN may be more prevalent in patients with $\mathrm{ICH}$ than in the general hypertensive population. Our data show that resistant HTN increases intensive interventions and LOS in the ICU without significant impact on short-term functional outcome at hospital discharge. 


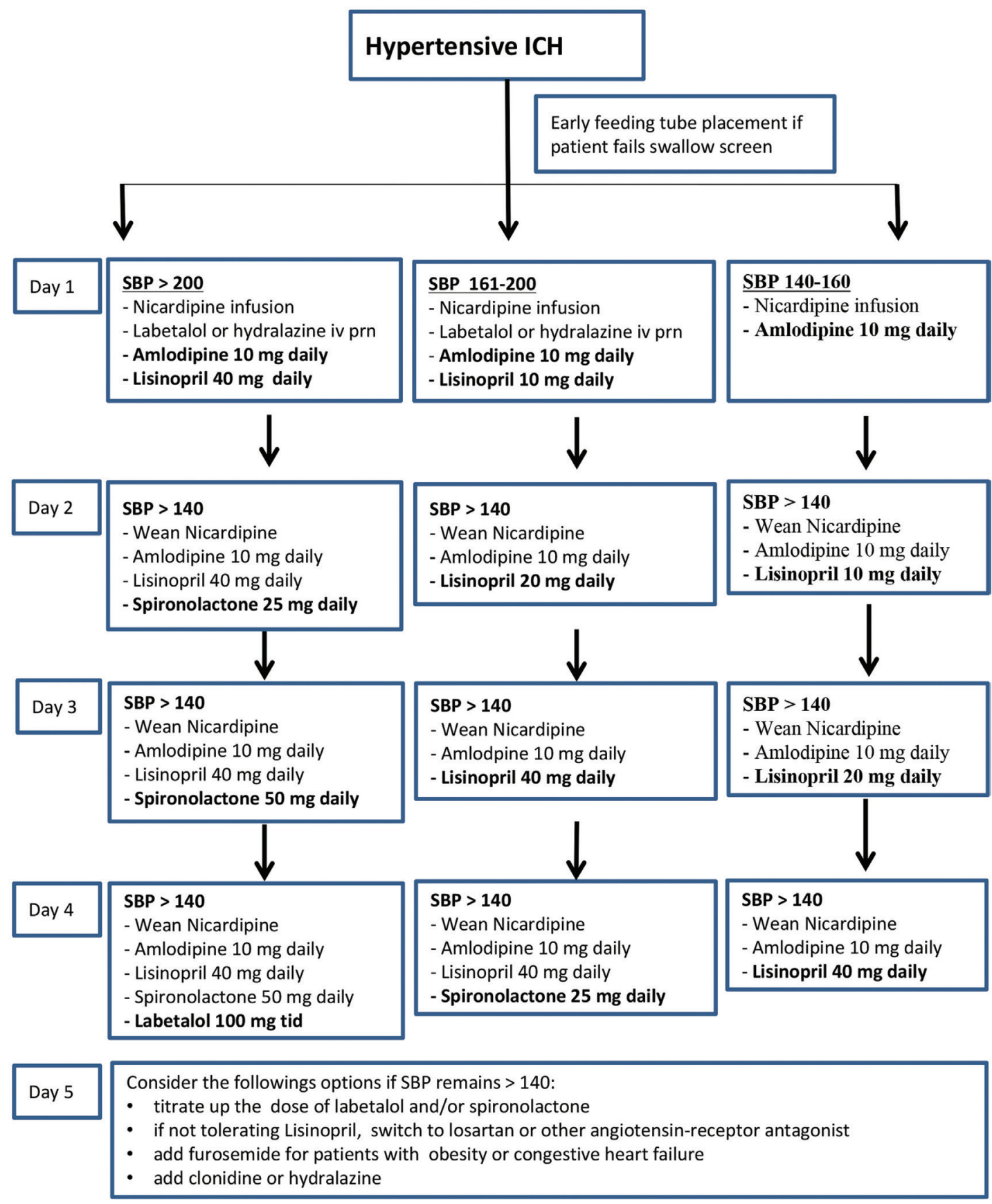

FIGURE 2 | Oral antihypertensive titration protocol for hypertensive intracerebral hemorrhage (ICH).

\section{ETHICS STATEMENT}

The study was approved by the Institutional Review Board of the University of California, Irvine.

\section{AUTHOR CONTRIBUTIONS}

DH: study design, data acquisition, analysis, interpretation, and drafting the manuscript. DS: acquisition of data and analysis. CD, YA, and LG: data interpretation and critical revision of the manuscript for important intellectual content. LA-K, JC, and SS: critical revision of the manuscript for important intellectual content. WY: study concept, design, data analysis, interpretation, and manuscript revision.

\section{FUNDING}

The research is conducted without any government or industrial funding. 


\section{REFERENCES}

1. Brott T, Thalinger K, Hertzberg V. Hypertension as a risk factor for spontaneous intracerebral hemorrhage. Stroke (1986) 17:1078-83. doi:10.1161/01. STR.17.6.1078

2. Meretoja A, Strbian D, Putaala J, Curtze S, Haapaniemi E, Mustanoja S, et al. SMASH-U: a proposal for etiologic classification of intracerebral hemorrhage. Stroke (2012) 43:2592-7. doi:10.1161/STROKEAHA.112.661603

3. Campbell GJ, Roach M. Fenestrations in the internal elastic lamina at bifurcations of human cerebral arteries. Stroke (1981) 12:489-96. doi:10.1161/01. STR.12.4.489

4. Auer RN, Sutherland GR. Primary intracerebral hemorrhage: pathophysiology. Can J Neurol Sci (2005) 32:S3-12.

5. Dandapani BK, Suzuki S, Kelley RE, Reyes-Iglesias Y, Duncan RC. Relation between blood pressure and outcome in intracerebral hemorrhage. Stroke (1995) 26(1):21-4. doi:10.1161/01.STR.26.1.21

6. Kazui S, Minematsu K, Yamamoto H, Sawada T, Yamaguchi T. Predisposing factors to enlargement of spontaneous intracerebral hematoma. Stroke (1997) 28(12):2370-5. doi:10.1161/01.STR.28.12.2370

7. Kim HC, Nam C, Jee SH, Suh I. Comparison of blood pressure-associated risk of intracerebral hemorrhage and subarachnoid hemorrhage: Korea Medical Insurance Corporation Study. Hypertension (2005) 46:393-7. doi:10.1161/01. HYP.0000177118.46049.e6

8. Manning L, Hirakawa Y, Arima H, Wang X, Chalmers J, Wang J, et al. Blood pressure variability and outcome after acute intracerebral haemorrhage: a post-hoc analysis of INTERACT2, a randomised controlled trial. Lancet Neurol (2014) 13:364-73. doi:10.1016/S1474-4422(14)70018-3

9. Tanaka E, Koga M, Kobayashi J, Kario K, Kamiyama K, Furui E, et al. Blood pressure variability on antihypertensive therapy in acute intracerebral hemorrhage: the stroke acute management with urgent risk-factor assessment and improvement-intracerebral hemorrhage study. Stroke (2014) 45:2275-9. doi:10.1161/STROKEAHA.114.005420

10. Manning LS, Rothwell PM, Potter JF, Robinson TG. Prognostic significance of short-term blood pressure variability in acute stroke: systematic review. Stroke (2015) 46:2482-90. doi:10.1161/STROKEAHA.115.010075

11. Anderson CS, Heeley E, Huang Y, Wang J, Stapf C, Delcourt C, et al. Rapid blood-pressure lowering in patients with acute intracerebral hemorrhage. N Engl J Med (2013) 368:2355-65. doi:10.1056/NEJMoa1214609

12. Qureshi AI, Palesch YY, Barsan WG, Hanley DF, Hsu CY, Martin RL, et al. Intensive blood-pressure lowering in patients with acute cerebral hemorrhage. N Engl J Med (2016) 375(11):1033-43. doi:10.1056/NEJMoa1603460

13. Hemphill JC, Greenberg SM, Anderson CS, Becker K, Bendok BR, Cushman M, et al. Guidelines for the management of spontaneous intracerebral hemorrhage: a guideline for healthcare professionals from the American Heart Association/ American Stroke Association. Stroke (2015) 46:2032-60. doi:10.1161/STR. 0000000000000069

14. Mohrien KM, Elijovich L, Venable GT, Taylor DR, Jones GM. Intensive blood pressure control during the hyperacute phase of intracerebral hemorrhage in patients at risk for resistant hypertension: a retrospective cohort study. J Crit Care (2015) 30:369-74. doi:10.1016/j.jcrc.2014.10.012

15. Calhoun DA, Jones D, Textor S, Goff DC, Murphy TP, Toto RD, et al. Resistant hypertension: diagnosis, evaluation, and treatment: a scientific statement from the American Heart Association Professional Education Committee of the Council for High Blood Pressure Research. Hypertension (2008) 51:1403-19. doi:10.1161/HYPERTENSIONAHA.108.189141

16. Sarafidis PA, Georgianos P, Bakris GL. Resistant hypertension - its identification and epidemiology. Nat Rev Nephrol (2013) 9:51-8. doi:10.1038/nrneph.2012.260

17. Sim JJ, Bhandari SK, Shi J, Liu IL, Calhoun DA, McGlynn EA, et al. Characteristics of resistant hypertension in a large, ethnically diverse hypertension population of an integrated health system. Mayo Clin Proc (2013) 88:1099-107. doi:10.1016/j.mayocp.2013.06.017

18. Kothari RU, Brott T, Broderick JP, Barsan WG, Sauerbeck LR, Zuccarello M, et al. The ABCs of measuring intracerebral hemorrhage volumes. Stroke (1996) 27:1304-5. doi:10.1161/01.STR.27.8.1304
19. Hemphill JC III, Bonovich DC, Besmertis L, Manley GT, Johnston SC. The ICH score: a simple, reliable grading scale for intracerebral hemorrhage. Stroke (2001) 32:891-7. doi:10.1161/01.STR.32.4.891

20. Ohwaki K, Yano E, Nagashima H, Nakagomi T, Tamura A. Impact of infection on length of intensive care unit stay after intracerebral hemorrhage. Neurocrit Care (2008) 8:271-5. doi:10.1007/s12028-007-9007-1

21. Naidech AM, Bendok BR, Tamul P, Bassin SL, Watts CM, Batjer HH, et al. Medical complications drive length of stay after brain hemorrhage: a cohort study. Neurocrit Care (2009) 10:11-9. doi:10.1007/s12028-008-9148-x

22. Nguyen C, Mir O, Vahidy F, Wu TC, Albright K, Boehme A, et al. Resource utilization for patients with intracerebral hemorrhage transferred to a comprehensive stroke center. J Stroke Cerebrovasc Dis (2015) 24:2866-74. doi:10.1016/j.jstrokecerebrovasdis.2015.08.023

23. Hafeez S, Behrouz R. The safety and feasibility of admitting patients with intracerebral hemorrhage to the step-down unit. J Intensive Care Med (2016) 31:409-11. doi:10.1177/0885066615578113

24. Fletcher JJ, Kotagal V, Mammoser A, Peterson M, Morgenstern LB, Burke JF. Cost-effectiveness of transfers to centers with neurological intensive care units after intracerebral hemorrhage. Stroke (2015) 46:58-64. doi:10.1161/ STROKEAHA.114.006653

25. Johnston SC, Mendis S, Mathers CD. Global variation in stroke burden and mortality: estimates from monitoring, surveillance, and modeling. Lancet Neurol (2009) 8:345-54. doi:10.1016/S1474-4422(09)70023-7

26. Stepanova M, Venkatesan C, Altaweel L, Mishra A, Younossi ZM. Recent trends in inpatient mortality and resource utilization for patients with stroke in the United States: 2005-2009. J Stroke Cerebrovasc Dis (2013) 22:491-9. doi:10.1016/j.jstrokecerebrovasdis.2013.03.005

27. Mayer SA, Brun NC, Begtrup K, Broderick J, Davis S, Diringer MN, et al. Efficacy and safety of recombinant activated factor VII for acute intracerebral hemorrhage. N Engl J Med (2008) 358:2127-37. doi:10.1056/ NEJMoa0707534

28. Mendelow AD, Gregson BA, Fernandes HM, Murray GD, Teasdale GM, Hope DT, et al. Early surgery versus initial conservative treatment in patients with spontaneous supratentorial intracerebral hematomas in the International Surgical Trial in Intracerebral Haemorrhage (STICH): a randomised trial. Lancet (2005) 365:387-97. doi:10.1016/S0140-6736(05)70233-6

29. Mendelow AD, Gregson BA, Rowan EN, Murray GD, Gholkar A, Mitchell PM, et al. Early surgery versus initial conservative treatment in patients with spontaneous supratentorial lobar intracerebral haematomas (STICH II): a randomised trial. Lancet (2013) 382:397-408. doi:10.1016/ S0140-6736(13)60986-1

30. Williams B, MacDonald TM, Morant S, Webb DJ, Sever P, McInnes G, et al. Spironolactone versus placebo, bisoprolol, and doxazosin to determine the optimal treatment for drug-resistant hypertension (PATHWAY-2): a randomized, double-blind, crossover trial. Lancet (2015) 386:2059-68. doi:10.1016/ S0140-6736(15)00257-3

Conflict of Interest Statement: The research was conducted in the absence of any commercial or financial relationships that could be construed as a potential conflict of interest. SS serves as editor-in-chief of the international journal Brain and Language and receives compensation from Elsevier Publishing for this service. He is also the recipient of funding from the National Institutes of Health under grants R13 DC011445, P01 HD040605, and P50 MH096889. WY serves as editorial board member for Frontier in Stroke, Stroke and Vascular Neurology and is scientific consultant for Stryker Neurovascular. Other coauthors report no disclosures.

Copyright (c) 2017 Hong, Stradling, Dastur, Akbari, Groysman, Al-Khoury, Chen, Small and $\mathrm{Yu}$. This is an open-access article distributed under the terms of the Creative Commons Attribution License (CC BY). The use, distribution or reproduction in other forums is permitted, provided the original author(s) or licensor are credited and that the original publication in this journal is cited, in accordance with accepted academic practice. No use, distribution or reproduction is permitted which does not comply with these terms. 